\title{
$\underline{\text { A Teaching Strategy on Euthanasia }}$
}

By: James M. Eddy and Wesley F. Alles

Eddy, J.M. \& Alles, W.F. (1982). A teaching strategy on euthanasia. Health Education,13, 6, 25.

Made available courtesy of Sage Publications: http://www.sagepub.com/

*** Note: Figures may be missing from this format of the document

\section{Article:}

The term euthanasia has developed a negative connotation over the last half century. Technically, the term was derived from the Greek "eu" meaning good and "thanatos" meaning death. Thus, euthanasia can be defined as "good death." But the term is often confused with mercy killing or a deliberate act which causes a death. Perhaps this controversy provides the impetus for the Euthanasia Education Council to change its name to Concern for Dying even though they function in basically the same capacity as in the past. For the purpose of this discussion, it is important to develop an operational definition of euthanasia and mercy killing. Hardt1 provides an excellent description of these concepts:

Voluntary euthanasia can be defined as the patient's granting of permission to allow for his death through removal or withholding of treatments that prolong life.

Involuntary euthanasia implies the allowance of death without the patient's knowledge through removal or withholding of treatments that prolong life.

Voluntary mercy killing can be described as the patient's granting permission for deliberate action to be taken causing death.

Involuntary mercy killing can be described as a deliberate action taken without the patient's knowledge that hastens death.

Obviously, there are still some gray areas among these definitions, but they do provide more clarity and basic operational definitions.

Much of the controversy surrounding this issue stems from a construct sometimes defined as "moral suffering." Because of recent advances in medical technology and transplantation, the definition of death has been clouded. As a result, medical personnel, patients, and family members must make decisions related to use of life sustaining equipment and procedures for which there is no clear-cut culturally defined value system. Therefore, from a health education perspective, it is important to provide students with structured learning experiences of a values clarification and decision-making nature. Perhaps such learning experiences will enhance the student's ability to deal with euthanasia situations in the future.

\section{References}

'Hardt, V. D. Death: The Final Frontier, Englewood Cliffs, New Jersey: Prentice-Hall Incorporated, 1979, p. 69.

${ }^{2}$ Eddy, J. M. and Alles, W. F. Death Education, St. Louis: The C. V. Mosby Company, 1983 
The activity which follows is designed to help students develop a definition of and a values position on euthanasia.

Title: Definitions of Euthanasia

Age Level: High School, College, Adults

Objective: Given a euthanasia case study, students will classify the situation as one of the following:

Voluntary indirect (passive) euthanasia

Involuntary indirect (passive) euthanasia

Voluntary direct (active) euthanasia

Involuntary direct (active) euthanasia

Material: Case study worksheet.

Directions: Provide students with a presentation of the contemporary interpretations of euthanasia. Develop a student worksheet of sample euthanasia situations (a sample worksheet is provided below). Ask students to classify the situation as one of the four types of euthanasia cited above. Conduct a classroom discussion on each of the situations.

\section{Definition of Euthanasia Worksheet}

Directions: For each of the euthanasia situations described below, identify how you believe this situation would be classified. Use the following symbols:

VIE-Voluntary indirect euthanasia

IIE-Involuntary indirect euthanasia

VDE-Voluntary direct euthanasia

IDE-Involuntary direct euthanasia

Stanley Kowalski, 27, was in a motorcycle accident and is paralyzed from the neck down. He is in severe pain. Every day when his close friend visits, he pleads that he be shot. Finally, the friend consents. Naomi Johnson, 62, has completed a Living Will. When she has a severe stroke, the family decides that no heroic measures should be taken to prolong Naomi's life.

Myrna Goldman, 56, has been diagnosed as having terminal lung cancer. Repulsed by the thought of proceeding through a long and painful treatment process, Myrna takes an overdose of sleeping pills. John Deluca, 43, is in a serious auto accident. There are definite indications that if John survives, he will live in a vegetative condition for the remainder of his life. The Deluca family decides to remove John from all forms of life-support systems.

Basil Worthington, 72, believes he has lived a useful and productive life. When he has a heart attack, Mr. Worthington opts not to sign the consent form for the required surgical procedures. 